\title{
Refugee Higher Education \& Participatory Action Research Methods: Lessons Learned From the Field
}

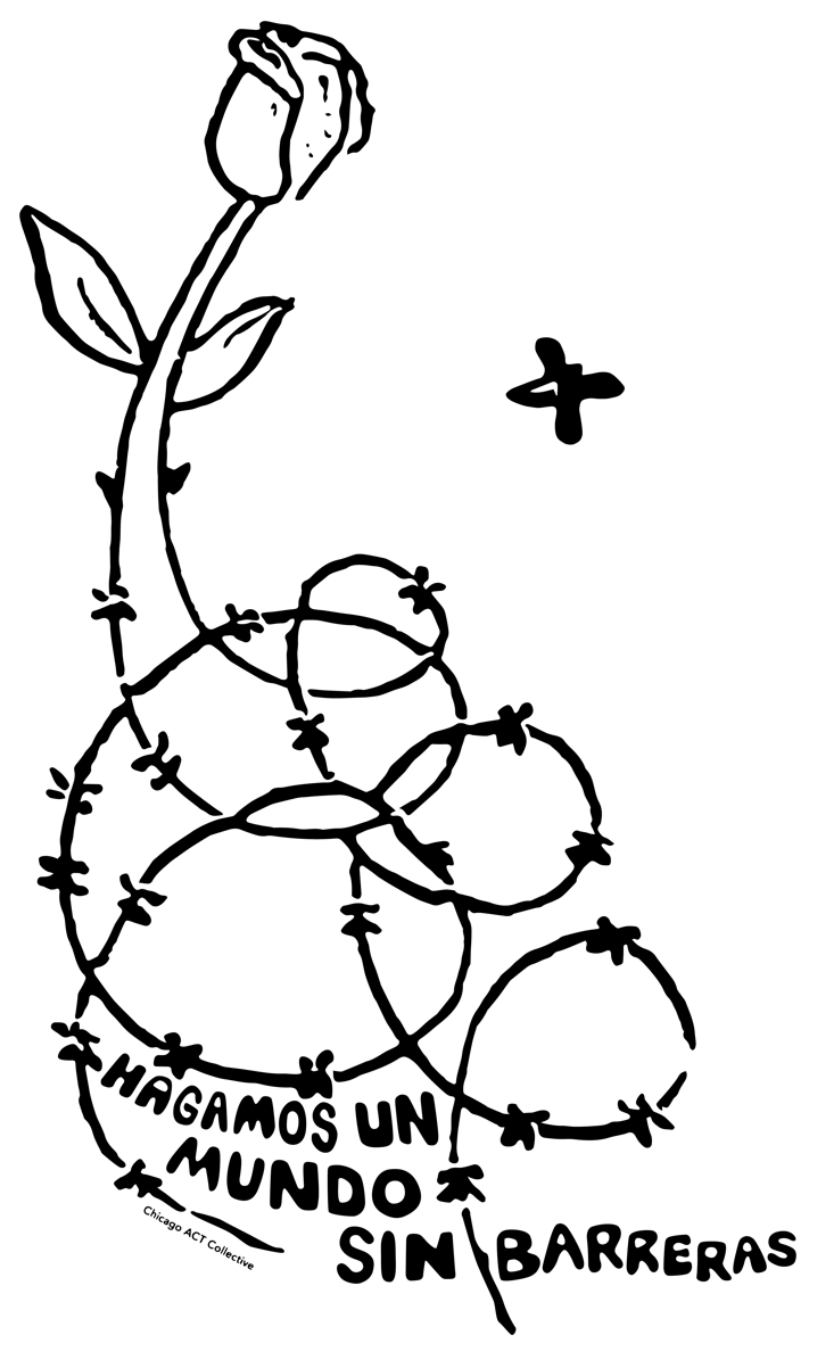


$\mathrm{I}$ $\mathrm{n}$ the following article, we review an online, higher education research initiative involving refugee learners, their experiences, and learning outcomes. Educators and other readers concerned with methods for participatory pedagogical practice in the digital realm may find our reflections of particular relevance and interest. It is no secret that the effects of COVID on higher education have been felt most dramatically by already underserved communities--delaying graduation for many in the best-case scenarios or contributing to higher drop-out rates and lower enrollments in the worst cases. Students, teachers, and academic administrators have had to adapt and find creative solutions to ensure higher education carries on uninterrupted. This article demonstrates a way, among many, in which technology and online education, as tools for adaptation, have transformed the way students access learning during COVID.

While technology requirements may have placed additional barriers in the way of completing a college degree for many students, for others, like GEM's refugee learners who are already well-versed in online learning, access to digital learning platforms represents a critical solution for expanding opportunities for skills-development and community-building beyond the refugee context. Combined with a participatory action research approach, learners also build a sense of agency and possibility--driving many to consider ways to support their own communities as problem solvers and changemakers. In this article, we demonstrate this participatory process and impact by reviewing a case study of a pilot research internship project, as part of the Global Education Movement (GEM), a program which partners with the South New Hampshire University (SNHU) to offer accredited, online college degree programs to refugees.

To help contextualize the role of higher education and GEM's participatory action research internship within the refugee context, it is important to point out that very few of the world's refugees are able to either return home, legally settle in the country to which they have fled or resettle to a third country. These options laid out by the international refugee response system are known as the "durable solutions." But with today's scale of displacement, the number of refugees that actually have access to these options is very small. That leaves the vast majority of refugees stuck in limbo in their host countries, dependent on aid and denied key rights such as the right to work, move freely, own property, and access public services. This reality requires us to think differently about how we can create new opportunities for refugees to lead a better quality of life. Fortunately, this growing recognition has led many humanitarian actors to prioritize alternative approaches, such as education and employment-based programming among other "complementary pathways," alongside resettlement.

Like other humanitarian actors and scholars, we believe a focus on higher education opportunities could be a welcome shift away from the historical tendency to view refugees as vulnerable or unable to determine their own futures. By contributing towards bolstering the agency of refugees to proactively find solutions to better their own lives and their communities through higher education, we can begin to move away from this reflexive, self-defeating narrative. Making efforts to engage refugees meaningfully as active participants in the identification and design of refugee solutions is fundamental to create this shift in perspective among refugees. Of course, this participatory action approach is not limited to the refugee context but can be applied to educational paradigms involving other underserved or marginalized communities. In the case of our research internship, skills-development is a participatory and applied experience in which refugee learners are given the opportunity to ask the hard questions, engage their own communities, and think through the answers based on their own life experiences--acknowledging the value of their own individual histories and perspectives.

This participatory approach can be a powerful catalyst for learners to reimagine themselves and their futures, despite the many uncertainties present in their lives. It can provide a unique sense of agency and possibility which is not typical in a traditional educational relationship of teacher to learner. For example, Deirdra (a pseudonym), a Congolese refugee living in a refugee camp near Cape Town, South Africa explained to me that she could never have imagined herself as a researcher. "That was always someone else's job," she said. She described coming into the program as a rather shy, but curious person. Going out and connecting with her community through the research assignments has made her want to learn more about her community members and find solutions to issues that she observes. As part of her degree, she is now taking part in a leadership training and volunteering in a women's support group for refugees.

But even beyond skills-development and building agency, the online internship has provided a unique opportunity to bring together refugee learners from multiple geographic sites within GEM's network, expanding the learning community across the boundaries of each physical location. For example, Trevor (a pseudonym), a refugee intern living in Kigali, Rwanda described the close bond that he formed with Deirdra from South Africa while working in the same group on research projects. Trevor hopes to be able to visit her one day. We were also struck when learning how exposure to interns from other sites may have stripped away some preconceived fears and cultural assumptions. During a conversation with Amina (a pseudonym), a Syrian intern living in Lebanon, she shared that at the start of the internship, she was concerned with how the other interns from outside Lebanon would perceive her dressed in a niqab, a type of face covering worn by some Muslim women. Amina felt uncomfortable turning her video on during online meetings for fear that she would be judged or misunderstood. But over the course of the internship, she explained that she realized that she actually had a lot in common with the other interns: "I actually started to feel like I was part of a family."

Participants, including interns as well as faculty become part of a global learning community in which they engage in a reciprocal learning experience. While the faculty serve as an essential bridge and resource to future professional development and networking opportunities, they also gain valuable exposure to the complex realities of being a refugee. Displacement may be the daily experience that 
may last several years; but an online learning community presents opportunities for meaningful connection and belonging to a wider community and where participatory learning approaches have the capacity to build new bridges and possibilities for a better future.

\section{Introduction}

Currently, only three percent $(3 \%)$ of refugees have access to higher education. Even as the rate of enrollment has improved from one percent ( $1 \%$ ) since 2018 , the results still pale in comparison to the global rate of higher education enrollment at 37\% (UNHCR 2019). There is no shortage of barriers making higher education as well as technical and vocational training inaccessible for young refugees. Poverty, marginalization, conflict and crisis all contribute to long periods of interrupted secondary education for many refugees. Proof of school certificates, language requirements, host country enrollment restrictions towards refugees, and the high costs associated with higher education add even more obstacles for refugee's accessing post-secondary education (UNHCR 2016). [Please note some scholars use the terms: post-secondary education, tertiary education and higher education interchangeably. For purposes of this article, we employ the term higher education.]

Yet, in an era when a refugee spends an average of 26 years in exile and as the number of forcibly displaced people continues to rise every year (UNHCR 2016), it becomes imperative to find accessible and sustainable solutions to bring higher education to refugees. While global initiatives and international agreements, like the 2018 Global Compact on Refugees or the 2019 Global Framework for Refugee Education call attention to this gap by pledging to ensure "an inclusive and equitable quality education" for all, there still remains work to be done to sufficiently address refugee barriers (UNHCR 2018). This includes raising completion rates and helping refugee graduates find suitable employment (Crea et al., 2015, Crea 2016., Crea et al., 2017; Reinhardt et al., 2018). What is promising is the growth in partnerships between local host communities, the private sector and academic institutions, which are paving the way for innovative solutions to fill this gap (Al-Husban et al., 2020). These consist of flexible or connected learning approaches that combine online and in-person teaching with mentoring and internship programs.

The Global Education Movement (GEM) is one such initiative that seeks to bridge the higher education gap among refugees by providing them with flexible learning opportunities. Partnered with the Southern New Hampshire University (SNHU), GEM offers competency-based, online university degrees to refugees in five different countries. Launched in the Kiziba refugee camp in Rwanda in 2013, the program has expanded to sites in South Africa, Kenya, Malawi and Lebanon, where students earn fully accredited and internationally recognized degrees (Russel et al., 2019). For students to apply and continue to build new skills and competencies, GEM combines online based instruction with paid internship opportunities, offered in partnership with local public, private and humanitarian institutions. The program currently serves over 1,000 students with $50 \%$ of participants being female and $98 \%$ of total participants graduating with an associates degree within two years (GEM 2020).

In 2020, continuing to expand its internship offerings, GEM, in partnership with faculty from the Graduate Center's City University of New York (CUNY), launched the Participatory Action Research (PAR) internship. Over the course of five months, three researchers and one graduate student provided online instruction to 21 refugee learners in qualitative and quantitative research methods. In this article, we review the current context of refugee higher education, its benefits and barriers facing refugees and the role of online learning within this context. We then describe the novel, pilot internship program and its use of the PAR framework. Next, we present the internship's approach and process and conclude with a discussion of its key findings, and recommendations for refugees and practitioners in the field.

\section{Literature Review}

Access to higher education plays a critical role in the lives of displaced people, as a transformative tool for selfempowerment and long-term stability, amid uncertain futures in their host communities (Crea 2015, Crea 2016, Arar et al., 2020). Higher education accelerates adaptation and improves life standards among refugees, while it potentially even mitigates future displacement from occurring (Arar et al., 2020). Here we discuss the importance of refugee higher education as well as the numerous challenges that make higher education unreachable for refugees. With a focus on the Global Education Movement (GEM), we then discuss the growth in innovative solutions to help meet this gap through blended or connected learning modalities that integrate blended learning models with professional development opportunities, such as the GEM PAR internship. As an experiential pedagogical practice, the PAR approach offers new insights for building agency and critical thinking among refugee learners, while providing an innovative research platform for the GEM program.

\section{Building Resilience through Refugee Higher Education}

Millions of refugees are living in protracted refugee situations, both in refugee camps and in urban areas. Of the 25.9 million refugees worldwide, over half are of school age children, with over four million not attending school. As refugee children get older, this education gap only widens, with roughly 23 percent of refugee children attending secondary school, compared to 84 percent globally (UNHCR 2019). Yet, even as the largest gap remains in refugee higher education, existing literature suggests that when higher education opportunities are made available, refugees are more likely to become self-reliant, confident and better 
able to cope with the complexity of their daily lives, often in protracted crisis conditions (Crea 2015, Crea 2016).

As a tool for building resilience, higher education offers refugees the opportunity to develop a "critical consciousness" by empowering students to have a voice and to serve as leaders and peacebuilders in their communities (Dryden-Peterson et al., 2010). Refugees understand that progressively higher levels of education lead to self-reliance, future livelihoods, and stability (Dryden-Peterson 2012). By engaging in higher education, refugees improve qualifications and gain the knowledge, skill sets, and selfefficacy to develop personally and professionally for longterm employability. Connecting to academic institutions enables refugee learners to build networks with teachers and peers, building their social capital in different contexts and helping them to establish pathways for future employability -- an essential step towards translating newly acquired degrees and skills into employment (Dryden-Peterson 2012; Crea 2016). While boosting levels of self-esteem and equipping refugees with the tools to problem solve and support their own communities, access to higher education increases their potential to engage as changemakers in their communities (Dryden-Peterson et al. 2012). Completion of higher education among older refugees alone serves as a "pull factor" for other younger refugees, driving many to complete their primary and secondary studies; thus, producing a rather significant ripple effect in the context of promoting self-sufficiency among refugees (WUSC 2018).

But providing accessible pathways to higher education is not only beneficial to the refugees themselves, it also benefits the host communities at large. Refugee learners perceive higher education as a key mechanism for being able to successfully integrate and contribute towards the social and economic fabric of the host country (Arar et al., 2020). With the socioeconomic means to support themselves, refugees also become less dependent on external aid to support their families (UNHCR 2016). In short, higher education expands livelihood opportunities for refugees who are then given the chance to advance and support themselves as professionals in their local communities.

Despite the clear benefits of higher education, for refugees, there is still limited access and countless hurdles. These barriers contribute to lower motivation levels among young refugees and deprives future generations of the knowledge and competencies necessary to contribute to the host country as well as potentially rebuild their home communities (Gladwell et al., 2016). Diminishing these roadblocks and finding ways to adapt educational modalities to fit the needs of refugees is an important strategy for improving refugees' social and economic stability.

\section{Barriers to Accessing Higher Education}

Ensuring higher education opportunities are accessible for refugees as well as equipping them for suitable employment is not a simple feat. Refugees wishing to enroll and successfully complete their studies face countless barriers. From the vantage of the host country, refugees are often identified as outsiders to the nation-state and may be excluded from a host country's higher educational system by lacking the required documentation or resources to participate (Zeus 2011; Al-Husban et al., 2020). The high costs associated with higher education institutions remain a major obstacle for refugees who are reliant on humanitarian aid to support them and their families (UNHCR 2019). As refugees grow older, they are expected to take on greater responsibilities in their families. Many have little choice but to go to work, often illegally or in the shadow economy, leading many to forgo a secondary education to provide for their families. Low enrollment in secondary education results in an even lower number of refugees in higher education.

But even for those who have completed secondary studies in their home country, school certificates, such as diplomas or birth certificates, are often left behind by refugees who flee their homes suddenly, which prevents many refugees from enrolling in local universities. But even when these documents are provided to host country universities, qualifications are not always perceived as equivalent (Naylor et al., 2019; UNHCR 2018). Similarly, language requirements in the host community are another way that higher education becomes inaccessible to refugees (Donald 2014; Gladwell et al., 2016). Despite being able to enroll in higher education, refugee learners also face limited access to electricity, technological devices, network connection and a lack of other infrastructural supports taken for granted in many developed locations. Nonetheless, while significant barriers exist to refugee higher education, research shows that leveraging technological advancements offers promising results to increase access (Dahya et al., 2016).

\section{Pathways to Refugee Higher Education: The Role of Technology}

While still underdeveloped, the emergence of digital technology within higher learning models has become a prominent approach in refugee higher education. Expanding the reach of higher education for refugees, these connected learning formats offer education opportunities in remote, low-resource communities typically excluded from formal schooling systems (Bauer 2020). For those refugees forced to work or stay home as caretakers, online learning offers a student centered, flexible format, which accommodates student schedules and other limitations that come with uncertain life circumstances. Being online means that instructors have a role in guiding students to self-learn and construct their own knowledge online, reinforcing the importance of basic to advanced computer skills. This method enables students to communicate, collaborate with peers and share resources, while using a wide range of internet-based tools (Crea et al., 2017). In the midst of uncertainty, an online education can provide a source of stability and growth for refugees, while access to technology helps them stay connected to each other, their families and other peer networks (Al-Husban et al., 2020). 
However, even with access to higher education, refugee learners may find themselves better educated, but lacking work opportunities and pathways to employment (McGrath 2012). Within blended learning models, which combine online learning with mentoring and internships where students can apply the skills they are learning, technology plays a central role in supporting refugee students beyond degree requirements. It helps refugee learners stay on track and connected to their peers and teachers (Dryen-Peterson et al., 2012). Such holistic approaches with additional nonacademic support, including mentoring and career development, can have a significant impact on their wellbeing and employment prospects (Dryden-Peterson 2012).

Later in the article, we discuss in more depth the topic of the 2019 Coronavirus pandemic (COVID-19) and its impact on the program. However, here, we would like to mention that in many ways, COVID-19 has accelerated global recognition of the essential role of technology and online learning in providing and maintaining higher education opportunities for refugees. The GEM program discussed in the next section was clearly ahead of the curve concerning online learning.

\section{The GEM Model}

Host governments, donors, and academic institutions are increasingly recognizing the value of connected or blended learning models for strengthening refugee prospects. This, in addition to the lower costs associated with implementing online education, are intensifying efforts to offer connected or blended learning opportunities in refugee communities, paving the way for partnerships with accredited degree programs. These initiatives have opened the doors to universities in higher resourced environments and to a larger pool of social and academic networks (Crea et al., 2016).

The Global Education Movement (GEM) is one such initiative which partners with the Southern New Hampshire University (SNHU) to offer a competency-based learning model that enables refugee learners to complete their studies at their own pace and practice acquired knowledge and skills during an internship. The goals or competencies outlined within a certain degree program or project are defined based on current industry standards and guidance from industry leaders and subject matter experts (Russel et al., 2019). For student assessments, direct feedback is provided by local faculty, known as reviewers, who provide input on a student's progress towards achieving a certain competency within the context of a project assignment.

Studies indicate that refugee higher education models that include internships linking learning programs to real world work scenarios boost motivation levels and sharpen the soft skills needed to succeed at any given job (UNHCR 2020; Dryden-Peterson et al., 2017). An online format helps ensure that refugees are equipped with both the technical and professional skills to engage in a digital work environment. Further, it can help educational programs engage directly with experts and practitioners active in their field, without the costs and delays of travel (UNHCR 2018). Internships that bring in experts with the latest technical skills and social capital can enhance the success of such professional training opportunities (World Bank 2019). Despite these clear benefits, scholars also highlight that distance-based staff and support would benefit from increased training and understanding related to the nuanced challenges commonly faced by refugees in these complex contexts (Dryden-Peterson et al., 2017). Within these online learning programs, it may be easy to overlook the complicated circumstances that many refugees face when not in the digital classroom.

Though successful, many of these educational initiatives have found it challenging to replicate at scale--to deliver a high quality and sustainable program and resolve unstable power sources and the resulting intermittent internet issues (UNHCR 2016; Reinhardt 2018). While this article does not seek to directly respond to these challenges, it describes the GEM model as one blended learning model that continues to expand its program offerings through partnerships with private, public, and academic institutions.

The GEM program, though nascent in its development, has made significant strides in scaling its learning opportunities to refugees in five different countries, including the participatory action research (PAR) internship. Offering the GEM PAR internship to multiple sites leveraged GEM's well-established support infrastructure and technological capacities to engage students based in multiple geographic locations. Additionally, it provided a unique, reflexive research platform to assess GEM programming and student experiences across sites in a collaborative environment.

\section{Participatory Action Research}

Beyond innovative modalities for helping refugees access higher education, existing literature also calls for dynamic pedagogical approaches. Especially needed are practices that can provide interactive and experiential programming that develop self-agency and critical thinking skills (Al Husban et al., 2020). As mentioned earlier, refugee protracted circumstances require different policies and pathways in order for refugees to be able to integrate into higher education (Arar et al., 2020). Introducing a participatory, learner-centered approach that values refugee experiences and perspectives helps refugees develop these critical thinking skills (Dryden-Peterson 2012).

Participatory Action Research (PAR), as a collaborative form of applied research, integrates social science inquiry with participant action and self-agency. While it engages participants in research practice and intervention simultaneously, the approach recognizes that participants have knowledge about how their own life situations could be improved and can contribute to the achievement of a more sustainable and effective outcome (Collie 2010). In short, the goal of this project, in line with the principals of PAR, was to utilize the expertise of the refugee learners in helping 
to develop the research project, collect the data, and interpret the results; all with the intent to make a positive contribution to the overall program and the lives of the refugee learners/researchers.

As the topic of (forced) migration grows within scientific scholarship, it becomes all the more relevant to equip displaced learners with the basic qualitative and quantitative skills necessary to conduct research in partnership with academic institutions, NGOs, UN agencies, the private sector, as well as all of their intersections. Such employment opportunities enable refugees to become changemakers-identifying issues impacting their own community and engaging its members to find their own solutions, as a way to bring about sustained impact.

We employed the PAR approach within the context of GEM's research methods internship because of its iterative and global approach. By iterative, we mean the entire research endeavor is an ongoing conversation between researchers and those being researched. The participants are involved in deciding which questions are asked, gathering the data, and most importantly, helping to interpret it. This leads to a 360-degree process where information is both gathered and produced by researchers, participants, and subjects, those who are studied, yet do not gather data. The following sections describe the GEM PAR internship pilot method and the resulting conclusions of this approach in teaching qualitative and quantitative research methods and its implications for refugee learners and educators.

\section{Methods}

As facilitators of the GEM PAR internship, we perceived the project as a developmental internship, one that equipped refugee participants with basic qualitative and quantitative skills and perspectives to become eligible to go on to support both academic and applied researchers. The internship program was supported by both GEM staff and volunteer researchers from the City University of New York's Graduate Center, the University of Illinois at Chicago, and the University of Illinois at Urbana/Champaign. Below, we describe the internship program structure and process.

\section{Recruitment}

Refugee participants in the GEM's PAR internship consisted of 21 interns ( 10 females and 11 males) from five different countries where GEM offers educational programming -- four interns from Dzaleka refugee camp in Malawi, three from Kakuma refugee camp in Kenya, five from multiple refugee camps in Lebanon, three from South Africa, and six from Kigali and Kiziba refugee camp, both located in Rwanda. An internship program of this magnitude, being offered by GEM to all of its sites, had never been considered prior to the GEM PAR program. Therefore, the initial design, planning and coordination were new to both the GEM team as well as the program facilitators who would be leading the internship.
In consultation with the lead researcher at the CUNY Graduate Center, interns were selected by GEM and its staff based on the quality and relevance of student CVs, cover letters, and English language proficiency. It was expected that the majority of interns had little to no prior instruction or experience in research methods. It is important to note that in addition to the skills and developmental professional experience offered by the GEM internship, the program provided all interns with a weekly stipend of $\$ 50.00$ for their participation. Such stipends are an important incentive for refugees to both enroll and maintain engagement. Out of a total of 63 applicants from all program sites, GEM shortlisted 31 students, and ultimately 21 students participated. As for internship facilitation, the lead supervisor, a Presidential Professor CUNY's Graduate Center invited three additional supervisors, two researchers from the University of Illinois and one graduate student from the Graduate Center to colead the internship within a tiered organizational structure, described in more detail in the next section.

Given that the GEM program and its students were already engaged in an online learning modality, all interns had access to the necessary technology, namely a computer device and an internet connection. Later, we will go into more detail to discuss the advantages and implications of this technology access and experience in the context of the Coronavirus pandemic. What is important to note here is that the majority of participating interns were already familiar with general online conduct and the basics of navigating online applications for effective engagement in a remote learning environment.

\section{Internship Management Structure}

The internship took place over a period of five months through an online-based platform and was divided into two phases: qualitative and quantitative research methods. To enhance collaboration among the interns and to ensure that we were able to provide direct and ongoing support, interns were divided into three groups, according to their respective geographic locations. Weekly, 90-minute sessions were facilitated by the lead supervisor. These sessions, where attendance was required by all interns, introduced new topics and assignments. These sessions were complemented by weekly two-hour meetings, organized by the group supervisor. The two-hour sessions served as an opportunity for interns, in a collaborative format, to receive more direct support on class content and assignments. Through this tiered structure, interns were exposed to their refugee peers from multiple sites, while they also received direct support from their immediate GEM PAR supervisors. GEM also provided additional support mechanisms by way of local partners at each GEM site.

\section{PAR Framework}

PAR's radical method, which perceives the subject as researcher, examines a research topic from the perspective of those who experience it, emboldening research subjects to become problem-solvers and active agents in the 
research process. Within the context of the GEM PAR internship, the lead supervisor, in collaboration with GEM staff identified research topics of particular relevance and utility to the GEM program and its refugee learners as a whole. As the internship was divided into two modules -qualitative and quantitative research methods -- each module generally examined the impact of Coronavirus on their college going experience and ultimately culminated in one research paper and/or presentation in which each group of interns worked collaboratively. During the first module on qualitative methods, each intern conducted a set number of interviews using the same set of questions and interview protocol in their respective site.

Consistent with this approach, within the second module on quantitative methods, we asked interns to investigate the impact of the Coronavirus pandemic on the educational experiences of GEM students compared to nonGEM students. Through the use of a survey administered in person, over the phone or online, interns identified non-GEM refugee learners and gathered the data individually. However, it was during the synthesis and presentation of the research in each module that interns shared their insights from their own experiences as GEM students -- discussing implications of the findings and proposing recommendations that could impact their own lives as well.

As an introductory course on the fundamentals of qualitative and quantitative approaches to research, interns were expected to leave the internship with a demonstrated understanding of the differences and applications of quantitative and qualitative research methods. Most assignments were completed as a group; individual interns completed specific tasks individually, which ultimately contributed to a larger assignment submitted by each group. This approach enabled interns to practice online team collaboration and the soft skills, including communication, interpersonal and time management skills, needed to work as a team in an academic or professional setting. Projects that required the use of Microsoft or Google applications, such as research papers, presentations or basic data analysis, demonstrated the hard skills necessary to excel in an academic research and/or a professional work environment.

\section{Learning Outcomes}

During the first module, focusing on qualitative research, interns:

1. were exposed to a variety of qualitative methods for gathering data; however, emphasis was placed on focus groups and one-on-one interviewing

2. individually developed proposals for a qualitative research project; each proposal had to answer (a.) what do you want to know, (b.) why do you want to know it, (c.) what do you think the answer is, and (d.) how will you find out?

3. given their proposal (see \#2 above), individually developed an appropriate interview protocol
4. via scholar.google.com, individually collected academic articles related to the content of their proposal as well as its methodology (one-onone interviewing)

5. within their groups, merged their individual interview protocols into one interview protocol that would be administered by each intern

6. given \#5 above, individually piloted the interview to three people

7. collaboratively worked within their groups to figure out which questions to keep versus alter versus jettison

8. individually administered the approved interview protocol to five people

9. collectively pooled and analyze all interviews

10. developed an appropriate white paper, explicating: (a.) the problem, (b.) the research question, (c.) the methodology, (d.) findings, (e.) given the findings, recommendations

11. using PowerPoint, collectively presented findings to internal and external stakeholders

During the second module, focusing on quantitative research, interns:

1. were exposed to a variety of quantitative methods for gathering data; however, emphasis was placed on surveys

2. individually developed proposals for a quantitative research project; each proposal had to answer (a.) what do you want to know, (b.) why do you want to know it, (c.) what do you think the answer is, and (d.) how will you find out?

3. given their proposal (see \#2 above), individually developed an appropriate survey

4. via scholar.google.com, individually collected academic articles related to the content of their proposal as well as its methodology (surveys)

5. within their groups, merged their individual surveys into one survey that would be administered by each intern

6. given \#5 above, individually piloted the survey to several people

7. collaboratively worked within their groups to figure out which questions to keep versus alter versus jettison

8. individually administered the approved survey to 30 people -- 15 GEM college students and 15 non-GEM college students

9. $\quad$ using excel, coded 30 interviews

10. collectively pooled and analyzed all surveys 
11. developed an appropriate narrative, explicating: (a.) the problem, (b.) the research question, (c.) the methodology, (d.) findings, (e.) given the findings, recommendations

12. using PowerPoint, collectively presented findings to internal and external stakeholders

13. Lastly, a final session of the internship focused on ways to translate their knowledge and skills gained during the internship onto the current job market. External research professionals and recruiters were brought to discuss some additional context on the relevance of research skills in the current job market.

\section{Findings}

Again, as a reminder and in keeping with the elements of participatory action research, the interns were actively involved with analyzing the data, deciding which 'stories' to tell from the findings, and then actually presenting those findings. Here, we discuss in some detail what those findings were. Even as connected learning initiatives play a crucial role in expanding higher education opportunities and employment pathways for refugee learners, it is not without its challenges (Bauer et al., 2020; Bolon et al., 2020; Crea 2016; Dahya et al., 2016). The GEM PAR internship reinforced the importance of having access to a reliable computer device and internet connection to ensure refugee engagement goes uninterrupted. During the internship, it was not uncommon to have interns absent from weekly meetings due to poor internet. In several of the locations where GEM's refugee learners are living, electricity is intermittent, computers or mobile devices are shared with family members, making computer and/or internet access weak or unreliable. Although GEM partners offer computer labs to its students, local crises do not always make it possible for students to travel to these sites when needed.

The GEM PAR pilot program was initially conceptualized as primarily an online internship, with international faculty teaching online and on-the-ground support staff in each GEM site. As the pilot evolved, it confirmed the importance of direct support mechanisms for refugee learners within flexible and connected learning models (Dryden-Peterson 2012). During the development stage of the internship, there was some concern that too large an internship might weaken the one-on-one support systems available to interns. However, the internship's tiered structure with multiple layers of direct supervision and weekly meetings meant that interns had access to numerous resources, including GEM PAR online supervisors as well as site specific, in-person GEM mentors available at each site. In fact, this tiered system provided skill and knowledge mentorship, as well as emotional and social support -- factors scholars claim are critical non-academic support mechanisms that boost refugee success in higher learning (Dryden-Peterson 2012).

Despite the advantages of online learning to promote digital skills building in an era increasingly reliant on digital platforms (Bauer et al., 2020), supervisors observed substantial variation in the levels of basic competencies across program sites. This variation in capacities to conduct basic tasks, such as using computer applications caused some supervisors to have to spend more time on teaching these hard skills directly instead of on the research methods concepts, contributing to delayed or incomplete assignments and adjustments to the overall internship syllabus. Feedback from program supervisors reinforced the need for further orientation before the start of the internship for participants and supervisors (Crea et al., 2017). As the program evolved, it became clear that a revised recruitment strategy, combined with a pre-program orientation would be beneficial to ensure interns are coming into the internship at the same level, while supervisors can prioritize teaching the primary content of the internship -- research methods.

Supervisors' dismay at participant skill-levels also supports the need for adequate orientation for the supervisors on refugee circumstances as well as on the internship curriculum prior to the start of the program (Crea et al., 2017). Without sufficient knowledge and awareness of the complex life situations of refugees, supervisors may have come with mismatched expectations on refugee learner academic capacities. Providing additional context and preparation for supervisors could help manage these expectations. Furthermore, supervisors also called for a reassessment of the recruitment strategy of interns, in addition to a pre-program developmental orientation, as mentioned above.

A compelling advantage of the online format was GEM's ability to extend the reach of the internship to multiple GEM sites simultaneously -- something that had never been done before due to foreseen logistical challenges and inadequate support structures for refugee learners. The program's novel approach to engage multiple GEM sites during one internship enabled cross border collaborations and comparison between GEM sites (Crea et al., 2017). Program supervisors and interns alike reported favoring the multi-site approach to the internship. One supervisor even remarked how the ability to work with interns across sites made it feel like we were all part of the same learning community. Despite the internship structure, which grouped participants by geographic area (e.g., all Syrian refugees in Lebanon in one group), participants enjoyed interacting and learning with other students from different regions. Reviewing each other's work during a peer review process, as well as listening to each other's presentations on a given assignment, enabled knowledge exchange on refugee circumstances across geographic areas. In fact, supervisors also learned about the experience of being a refugee through their interns in ways that may have not been possible without a remote learning platform, bridging refugee learners with overseas faculty. Supervisors advocated to mix the groups across program sites to enable more exchange and collaboration across the geographic areas and participant experiences.

In addition, language barriers may be hindering some students from fully engaging in the GEM PAR internship. As the overseas faculty facilitated the internship in English, there was some concern that delayed student submissions 
were due, in part, to English language proficiency levels among participants. Interns commented on the fast pace at which the classes were taught. One student repeatedly noted that they relied heavily on the session recordings that were shared after each class to fully comprehend class concepts and assignments. Others with low English proficiency reported relying on their peers to understand class content and expectations. Supervisor feedback also reinforced the fact that classes were communicated, using American colloquialism, which not all students were familiar with. An adjusted pace and use of more 'global' English could enhance class comprehension.

Though still early to know the full implications on participant employment outcomes, bringing international faculty from well-resourced universities has great potential to expand GEM's intellectual and social capital across borders (Crea et al., 2016). While gaining new knowledge, GEM interns have the opportunity to expand their networks to a wider pool of educators, scholars, and professionals, which studies suggest boosts employment outcomes (ElGhali et al., 2019).

\section{Impact of COVID}

This paper would be incomplete if we did not include some discussion on the negative and unexpected (positive) impacts of COVID-19 on refugee learning. COVID-19 was first identified in December 2019 in Wuhan, China. After the World Health Organization (WHO) declared the outbreak as a Public Health Emergency of International Concern and a pandemic in March 2020, countries around the world began experiencing the first wave of virus infections (WHO). Shortly after the U.S. declared COVID-19 as a public health emergency, a variety of sweeping lockdown measures were implemented across the country. These included the temporary closures of most businesses and restaurants that involved in-person interactions or public gatherings. Additional measures to stop the spread of the virus included mask-wearing, social distancing, travel restrictions, and more. However, for many of those fortunate enough to have access to technology, remote working and learning has become the new normal, including for most U.S.-based universities.

Throughout Africa and Lebanon, where GEM sites are located, COVID-19 first appeared in February 2020 and has had drastic implications for those in schools. In Africa, measures to contain the virus varied across the continent, as many countries banned public gatherings, including sweeping school closures starting in May 2020. In Lebanon, all educational institutions were ordered to close shortly after the country identified its first case in February. For forcibly displaced communities in these contexts, COVID-19 has had a dramatic impact on all aspects of their lives, including health, safety, education, and community access. While many primary and secondary schools in refugee contexts have resorted to deliver lessons through broadcast radio, outdoor classes, among other creative solutions, others have had to delay school lessons for extended periods of time, lacking the personal protective equipment or sufficient measures in place to ensure safety for teachers and students (UNHCR 2020). However, for many refugees, access to technology and online learning has served as a lifeline in preventing delays in studies.

For the GEM PAR internship, a fully online based internship was a unique opportunity, given travel and social distancing measures, to leverage GEM's technological capacities and infrastructure. Three of the four supervisors are professors who all had to adapt to teaching remotely from their own campuses starting in March 2020. As the GEM PAR internship began in June, supervisors had several months to adjust to this new online modality. The interns, having already been exposed to GEM's blended learning model were largely familiar with the basics of online learning. Because their curriculum was already $100 \%$ online, GEM students were somewhat protected from the full negative impact of having to learn via Zoom.

COVID-19 also factored into the content of both the qualitative and quantitative research. Each module had questions focusing on how COVID-19 affected the learning process, comparing GEM students with non-GEM students. Because COVID-19 prevented face-to-face interviewing, the Lebanon group utilized Google applications to administer their survey, learning to leverage digital tools to overcome research limitations. The results of this research across sites demonstrated that GEM students were better prepared to be fully online and more insulated from COVID-19 related interruptions to their studies, compared to other university students who experienced considerable delays.

\section{Conclusion, Implications, and Recommendations}

Given the qualitative nature of the data, we are not able to generalize our program or the findings from data collected by the interns to other refugee populations or higher education programs. Data was only collected over the course of five months, a relatively short-time frame and may not fully capture changing dynamics of online education delivery within and across sites. Although the study tries to capture the perspectives and feedback of GEM staff, internship supervisors and students, it does not capture the view of on-site program staff, who could certainly enrich the study in understanding how student performance and capacities for participating in GEM PAR compare with others at each GEM site.

These limitations notwithstanding, it is clear that engaging students in participatory action research methods, and especially across multiple sites, provides a powerful reflexive learning community. As the internship looks to its next phase of implementation, it has expanded its scope to more than double the number of interns to more than 50 and increased the number of supervisors from three to six. One novel addition to the next phase of the program is the recruitment of interns from the first internship pilot to serve as program managers who will provide support to the supervisors. 
As programs seeking to provide higher education to refugees are on the rise, there is a need for sustained focus on evidence building and sharing best practices across various program models and relevant stakeholders. Future research on online educational programming could look at comparing in-person and online support mechanisms on refugee study outcomes. Even more relevant to the GEM PAR would be to examine employment outcomes as a result of the GEM PAR internship on refugee participants. This could help to better identify skill-gaps among refugees interested in building further their research skills and/or ways to merge a PAR learning experience with other competencies to enhance their career prospects.

Finally, given what we have learned from the GEM PAR program in its first iteration, here we highlight practical recommendations for consideration among scholars, practitioners, and others interested in planning and implementing a similar project for refugee learners. First, supervisors should be mindful that English is a second language for most interns. Interns are at once learning new research methods skills, while also learning the English language. Adjusting vocabulary and pace of speech can help ensure comprehension. Second, interns across different sites can be grouped together to maximize academic collaboration and cultural exchange across geographic sites. More specifically, if there are five sites, then each group should have interns from all five sites. Third, once assessed for both technical skills and English language capacities, interns can be grouped across skill-level to allow for peer learning opportunities when collaborating on group assignments.

Fourth, to orient and prepare incoming GEM PAR supervisors to work with refugee learners, GEM staff can consider providing a brief introduction on the cultural and political context of each refugee site, as well as guidance on working with and supervising refugee interns. As some supervisors were unaware of the lack of certain technical capacities among the interns at the university level, GEM can consider clarifying the intent of the internships as more of a developmental internship that seeks to help students to gain necessary hard and soft skills before being eligible to apply for internships at a prospective employer. Fifth, to prepare prospective interns to take part in the GEM PAR internship, GEM staff can consider providing a prerequisite study skills workshop, which could include basic writing skills, drafting a presentation on PowerPoint, collaborating on Google drive, taking notes during class, etc. Team building activities can also help interns learn to collaborate with one another and demonstrate commitment to a group project or task.

\section{References}

Al-Husban, N., \& Shorman, S. (2020). Perceptions of syrian student refugees towards blended learning: Implications for higher education institutions, International Journal of Emerging Technologies in Learning (iJET), 15(1), 45-60.

Arar, K., Kondakci, Y., \& Streitwieser, B. (2020). Higher Education for Forcibly Displaced Migrants, Refugees and Asylum Seekers, Higher Education Policy, 1-8.

Bauer, C., \& Gallagher, M. J. (2020). Education for Humanity: higher education for refugees in resourceconstrained environments through innovative technology, Journal of Refugee Studies, 33(2), 416-436.

Bolon, I., Mason, J., O'Keeffe, P., Haeberli, P., Adan, H. A., Karenzi, J. M., ... \& Martins, S. B. (2020). One Health education in Kakuma refugee camp (Kenya): From a MOOC to projects on real world challenges, One Health, 10, 100158.

Collie, P., Liu, J., Podsiadlowski, A., \& Kindon, S. (2010). You can't clap with one hand: Learnings to promote culturally grounded participatory action research with migrant and former refugee communities, International Journal of Intercultural Relations, 34(2), 141-149.

Crea, T. M., \& McFarland, M. (2015). Higher education for refugees: Lessons from a 4-year pilot project, International Review of Education, 61(2), 235-245.

Crea, T.M. (2016). "Refugee higher education: Contextual challenges and implications for program design, delivery, and accompaniment," International Journal of Educational Development, Elsevier, vol. 46(C), pages 1222.

Crea, T.M., Sparnon, N. (2017). Democratizing education at the margins: faculty and practitioner perspectives on delivering online tertiary education for refugees, Int J Educ Technol High Educ 14, 43.

Dahya, N., and Sarah Dryden-Peterson. (2016). Tracing Pathways to Higher Education for Refugees: The Role of Virtual Support Networks and Mobile Phones for Women in Refugee Camps, Comparative Education (December): $1-18$.

Dryden-Peterson, S., \& Giles, W. (2010). Higher education for refugees. Refuge: Canada's Journal on Refugees, 27(2), 3-9.

Dryden-Peterson, S. (2012). The Politics of Higher Education for Refugees in a Global Movement for Primary Education, Refuge, 27(2), pp. 10-18.

Dryden-Peterson, S. (2016). Refugee education: The crossroads of globalization. Educational Researcher, 45(9), 473-482.

Dryden-Peterson, S. (2017). Refugee education: Education for an unknowable future, Curriculum Inquiry, 47:1, 1424.

El-Ghali, H. A., Alameddine, F., Farah, S., \& Benchiba, S. (2019). Pathways to and Beyond Education for Refugee 
Youth in Jordan and Lebanon. Beirut: Issam Fares Institute for Public Policy and International Affairs (IFI), American University of Beirut, and Abdulla Al Ghurair Foundation for Education.

Gladwell, C., Hollow, D., Robinson, A., Norman, B., Bowerman, E., Mitchell, J., Floremont, F., Hutchinson, P. (2016). Higher education for refugees in low-resource environments: research study, Jigsaw Consult, United Kingdom.

Global Education Movement (2020), https://gem.snhu.edu/.

McGrath, S. (2012). Vocational education and training for development: a policy in need of a theory? Int. J. Educ. Dev. 32, 623-631.

Naylor, R., Terry, L., Rizzo, A., Nguyen, N., \& Mifsud, N. (2019). Structural Inequality in Refugee Participation in Higher Education, Journal of Refugee Studies.

Russell, C. \& Weaver, N. (2019). Going Global to Meet the Needs of Refugee and Displaced Learners, EDUCAUSE Review 54, no. 4 (Fall 2019).

Reinhardt, S. (2018). Exploring the Emerging Field of Online Tertiary Education for Refugees in Protracted Situations, Open praxis 10.3 (2018): 211-220.

UNHCR. (2020). Coming Together: For Refugee Education. 2020 Report.

UNHCR. (2019). Tertiary Education out of Reach. 2019 Report.

UNHCR. (2018). Turn the Tide: Refugee Education in Crisis. 2018 Report.

UNHCR. (2016). Aiming Higher: The Other One Percent. 2016 Report.

World Bank Group. (2019). The Changing Nature of Work. 2019 World Development Report.

Zeus, B. (2011). Exploring barriers to higher education in protracted refugee situations: The case of Burmese refugees in Thailand, Journal of Refugee Studies, 24(2), 256-276.

\section{Acknowledgements}

The authors wish to thank the entire GEM team and its partners, including Christina Russell, GEM's Executive Director; Nina Weaver, Director of Partnerships and Research; Nadia Asmal, Associate Director of Livelihoods and Advocacy, and Emmanuel Ushindi who provided ongoing support and made the GEM PAR internship possible. A big thank you also to the supervisors of the GEM PAR internship, professors Dov Cohen and Natalie Bennett for their valuable commitment and facilitation during the internship. A special thanks to all the GEM PAR interns who participated in the first cohort.

(c) (7)

ULIS D-Sulf
This work is licensed under a Creative Commons Attribution 4.0 International License.

This journal is published by the University Library System of the University of Pittsburgh as part of its D-Scribe Digital Publishing Program, and is cosponsored by the University of Pittsburgh Press. 